ks. Roman Pindel

\title{
O potrzebie ekskulturacji w procesie inkulturacji
}

W niniejszym artykule pragniemy uzasadnić potrzebę ekskulturacji, która naszym zdaniem winna towarzyszyć procesowi inkulturacji ${ }^{1}$. Wpierw jednak zestawimy terminy bliskoznaczne odnoszące się do przenikania elementów różnych kultur. Przywołamy także biblijne przykłady inkulturacji, by na końcu przedstawić propozycje realizacji ekskulturacji.

\section{Kwestie terminologiczne}

Termin ,inkulturacja”, choć zadomowił się już na dobre w antropologii kultury, socjologii, teologii i nauczaniu Kościoła, stanowi neologizm, który wciąż bywa w różny sposób określany. Zbliżony co do znaczenia termin „transkulturacja” jest odnoszony do faktu rozszerzania się elementów jednej kultury na drugą poprzez przejęcie, zapożyczenie (niekiedy pod przymusem). Ma przy tym miejsce selekcja oraz transformacja przenoszonych wzorów. Bliski znaczeniowo wobec inkulturacji, choć także w różny sposób określany, jest termin „akulturacja”2. W. Piwowarski, socjolog religii, w akulturacji podkreśla element przejmowania elementów z kultury obcej wobec tej, w której dany człowiek lub grupa wcześniej byli już zakorzenieni (to określa termin „enkulturacja”) ${ }^{3}$. Z kolei J. Chmiel, biblista, z ,akulturacją” wiąże wzajemną wymianę (osmozę) między różnymi kulturami, termin ,inkulturacja” określa zaś jako „proces wchodzenia przekazu

${ }^{1}$ Termin „ekskulturacja” rozumiemy jednak zdecydowanie inaczej niż francuska socjolog Danièle Hervieu-Léger, która definiuje „exculturation” jako proces wykluczenia katolicyzmu ze świeckiej kultury, a co opisuje w książce pod znamiennym tytułem, stanowiącym równocześnie diagnozę w odniesieniu do sytuacji Kościoła we Francji: Catholicisme, la fin d'un monde, Paris 2003.

${ }^{2}$ Oba terminy wymienia obok siebie, jakby były synonimiczne, adhort. apost. Catechesi tradendae, 53.

${ }^{3}$ Por. W. Piwowarski, Akulturacja, [w:] Słownik katolickiej nauki społecznej, red. nauk. W. Piwowarski, Warszawa 1993, s. 14. 
Objawienia w kulturę lub kultury, której formy, wartości i język udzielają mu nieodzownych środków do historycznego uzewnętrznienia się"4.

Najszerzej pojmowana inkulturacja przewiduje dwa zasadnicze sposoby przenikania elementów szeroko pojętej kultury. W jednym idzie o przekaz między pokoleniami, w drugim między różnymi kulturami. Składowe procesu inkulturacji wymienia J. Baniak, gdy pisze: „U podstaw procesu inkulturacji religijnej znajduje się obiektywnie pojęta kultura religijna, uwzględniająca: a) wierzenia i wyobrażenia religijne danej grupy społecznej, b) wzory kulturowe manifestowania tych wierzeń i wyobrażeń (praktyki pobożności), c) wzory przekazywania pobożności w procesie wychowania i socjalizacji, d) kulturowe rezultaty wierzeń w postaci norm moralnych i obyczajowych, e) wzory dotyczące stylu życia (np. rodzinnego)"

Powszechnie przyjmuje się, że terminu ,inkulturacja” po raz pierwszy użył w roku 1962 J.-M. Masson $\mathrm{OMI}^{6}$, który mówił wówczas o „konieczności inkulturowanego katolicyzmu" ". Ponad 10 lat później termin ten pojawił się w dokumentach XXXII Kongregacji Generalnej Jezuitów (1974/1975), a następnie w roku 1977 - prawdopodobnie za sprawą P. Arrupego SI - w dokumencie końcowym Synodu Biskupów w Rzymie pt. Ad populum Dei nuntius (nr 5). Jednak przełomowe znaczenie miało użycie terminu „inkulturacja” w adhortacji apostolskiej Catechesi tradendae (nr 53) z 16 października $1979^{\circ}$. W tym samym roku temat inkulturacji podejmowano na sesji plenarnej Papieskiej Komisji Biblijnej ${ }^{9}$, a następnie w dwóch dokumentach Międzynarodowej Komisji Teologicznej (w roku $1985^{10}$

${ }^{4}$ Por. J. CHMIEL, Inkulturacja a teologia biblijna; [w:] Studium scripturae anima theologiae. Prace ofiarowane księdzu profesorowi Stanisławowi Grzybkowi, red. J. Chmiel, T. Matras, Kraków 1990, s. 45. W innym swoim artykule J. Chmiel formułuje propozycję badawczą odnośnie do zagadnienia inkulturacji - por. Das Inkulturationsproblem in heutiger Schriftauslegung, „Analecta Cracoviensia” 19 (1987), s. 406-408.

${ }^{5}$ J. BANIAK, Inkulturacja, [w:] Encyklopedia PWN. Religia, t. 5, s. 41.

${ }^{6}$ Choć za twórcę uchodzi jego nauczyciel P. Charles SI, autor znaczącego artykułu Missiologie et Acculturation, „Nouvelle Revue Théologique” (1953), s. 15-32.

${ }^{7}$ Por. J.-M. Masson, L'Église ouverte sur le monde, „Nouvelle Revue Théologique” 84 (1962), s. 1032-1043.

${ }^{8}$ Por. G. Collet, Inkulturation. I. Begriff und Problemstellung, [w:] Lexikon für Theologie und Kirche, hrsg. von W. Kasper, t. 5: Hermeneutik bis Kirchengemeinschaft, Freiburg 2006, s. 504-505.

${ }^{9}$ Por. Fede e cultura alla luce della Bibbia. Foi et culture à la lumière de la Bible. Atti della Sessione plenaria 1979 della Pontificia Commissione Biblica, Torino 1981.

${ }^{10}$ Por. Themata selecta de Ecclesiologia occasione XX anniversarii conclusionis Concilii Oecumenici Vaticani II, Libreria Editirice Vaticana 1985, rozdz. 4: Populus Dei et inculturatio (Commissio Theologica Internationalis. Documenta, 13). 
oraz $1988^{11}$ ). W ostatnim z nich (Wiara i inkulturacja) wpierw określa się inkulturację jako „wysiłek Kościoła zmierzający do wprowadzenia orędzia Chrystusa w określone środowisko społeczno-kulturalne, wzywając do wiary według wszystkich jej własnych wartości, uwzględniwszy, że są one do pogodzenia z Ewangelią" 12 , następnie zaś przywołano określenie wzięte z encykliki Slavorum apostoli: „Inkulturacja [jest] wcieleniem Ewangelii w rodzime kultury oraz wprowadzeniem tych kultur w życie Kościoła” (nr 21). Dokument Papieskiej Komisji Biblijnej Interpretacja Biblii w Kościele (1993) inkulturacji poświęca cały rozdział (IV B), w nim zaś na szczególną uwagę zasługuje fragment, który określa „teologiczny fundament inkulturacji”. Stanowi go „przekonanie wiary, że Słowo Boże transcenduje kultury, w których zostało wyrażone i ma zdolności rozprzestrzeniania się w innych kulturach tak, aby dotrzeć do wszystkich ludzi w tym kontekście kulturowym, w którym żyją" (tł. D. Piekarz) ${ }^{13}$.

\section{Proces inkulturacji w Biblii}

Z dokonanego przez nas przeglądu określeń i wypowiedzi wynika, że inkulturacja to proces dwustronny, w którym orędzie biblijne, wpierw sformułowane w jednej kulturze, zyskuje nowy wyraz w innej, z której do wcześniejszej zostają przejęte nowe i ubogacające elementy, a które są niesprzeczne z orędziem chrześcijańskim. Takie rozumienie tego procesu wyraził Jan Paweł II w czasie spotkania z prezydentem Grecji w Atenach (4 maja 2001). Mówił wówczas: „Inkulturacja Ewangelii w świecie greckim pozostaje wzorcem wszelkiej inkulturacji. Nawiązując relację z kulturą grecką, głosiciele Ewangelii musieli podejmować wysiłek jej wnikliwego rozeznawania, aby przyjąć i wykorzystać wszystkie elementy pozytywne, a zarazem odrzucić te, których nie można było pogodzić z chrześcijańskim orędziem"14.

Zanim jednak doszło do inkulturacji Ewangelii w świecie greckim, wcześniej miało miejsce spotkanie religii judaizmu palestyńskiego z bogactwem kultury hellenistycznej ${ }^{15}$, którego owocem jest m.in. Septuaginta. Jeszcze

${ }^{11}$ Por. Wiara i inkulturacja, [w:] Od wiary do teologii. Dokumenty Międzynarodowej Komisji Teologicznej 1969- 1996, red. J. Królikowski, Kraków 2000, s. 251-269.

${ }^{12}$ Wiara i inkulturacja, 10, [cyt. za:] Od wiary do teologii..., dz. cyt., s. 255.

${ }^{13}$ Cyt. za: Z badań nad Biblia. Prace katedry Teologii i Informatyki Biblijnej Wydziału Teologicznego Papieskiej Akademii Teologicznej w Krakowie, t. 2, Kraków 1998, s. 178.

${ }^{14} \mathrm{O}$ weryfikacji kultury ze względu na wartości ewangeliczne w sposób podobny wyraża się dokument Interpretacja Biblii w Kościele (IV. B).

${ }^{15}$ Proces ten ukazuje M. Hengel w znakomitej, trzykrotnie wznawianej rozprawie habilitacyjnej Judentum und Hellenismus. Studien zu ihrer Begegnung unter besonderer Berücksichtigung Palästinas bis zur Mitte des 2. Jh.s v. Chr., Tübingen $1988^{3}$ (Wissenschaftliche Untersuchungen zum Neuen Testament, 10). 
wcześniej miała miejsce inkulturacja w dziejach Izraela, gdy różne tematy teologiczne były formułowane w kolejnej tradycji. Dla ilustracji tego procesu, którego ślady znajdujemy na kartach Biblii, wystarczy zestawić dwa zapisy ostatniego przykazania Dekalogu, jeden z Wj 20, 17, drugi z Pwt 5, 21:

„Nie będziesz pożądał (לז תַחמרז) domu bliźniego twego. Nie będziesz

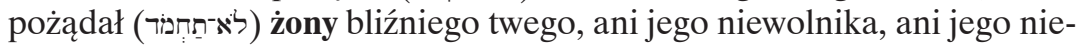
wolnicy, ani jego wołu, ani jego osła, ani żadnej rzeczy, która należy do bliźniego twego" (Wj 20, 17 według Biblii Tysiąclecia).

„Nie będziesz pożądał (לא תַחְמר) żony swojego bliźniego. Nie będziesz

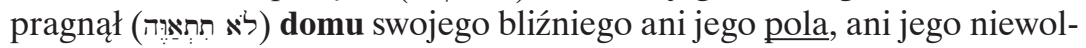
nika, ani jego niewolnicy, ani jego wołu, ani jego osła, ani żadnej rzeczy, która należy do twojego bliźniego" (Pwt 5, 21 według Biblii Tysiąclecia).

Pomijając wiele zagadnień szczegółowych ${ }^{16}$, łatwo dostrzec, iż ta sama zasada poszanowania stanu posiadania bliźniego (רֵ) została wyrażona w dwóch nieco różniących się sformułowaniach, w których znajdują odbicie uwarunkowania społeczno-ekonomiczne i kulturowe. W zapisie później datowanym (Pwt 5, 21), stanowiącym rodzaj inkulturacji wcześniejszego sformułowania (Wj 20,17) pojawia się pole (שָׁ) wskazujące na zmianę w sytuacji Izraela. Po przejściu z formy życia nomadycznego do osiadłego, a przede wszystkim po podziale ziemi Kanaan pojawia się możliwość pożądania i naruszenia własności w postaci kawałka pola. Pomiędzy obydwoma zapisami doszło także do zmiany w określeniu miejsca kobiety (איָָׁ) W rodzinie. We wcześniejszym sformułowaniu (Wj 20,17) stanowi ona część domu (בְּית) posiadanego przez mężczyznę, w późniejszym jest traktowana na sposób osoby, a nie ,inwentarza”, na co wyraźnie wskazuje szyk zdania w wersecie Pwt 5, 21.

Inkulturacja jest poświadczona w Biblii choćby przez fakt, że zbawienie wszystkich narodów zostało zapośredniczone w jednym narodzie. Początek narracji o Abrahamie, protoplaście narodu wybranego, został osadzony w kontekście dziejów świata tworzonego przez wiele narodów, języków i kultur (Rdz 10-13) ${ }^{17}$. Inkulturacja ma miejsce w dziejach Izraela ze względu na zmieniające się okoliczności, w których żyje, ale także poprzez sposób zorganizowania życia społecznego i narodowego oraz zmieniające się formy religii. Wszak Izrael przechodzi od stylu życia nomadycznego do osiadłego; od statusu mniejszości w Egipcie, przez konkwistę ziemi Kanaan do własnej państwowości; poprzez wygnanie babilońskie i kolejne niewole do różnych

${ }^{16}$ Choćby problem bliższego określenia znaczenia użytych terminów por. S. ŁacH, Księga Powtórzonego Prawa. Wstęp, przekład, komentarz, Poznań 1971, s. 139-140 (Pismo Święte Starego Testamentu, 2.3).

${ }^{17}$ Wskazuje na to dokument Interpretacja Biblii w Kościele (IV. B). 
form życia w rozproszeniu. W związku z nowymi okolicznościami zmienia się sposób zorganizowania życia społecznego, narodowego i religijnego ludu Bożego: od grupy nomadów do grupy plemion, które pilnie strzegą swego stanu posiadania po uprzednim podziale ziemi; od amfiktionii do królestwa; od utraty niepodległości i przymusowej emigracji do prób uzyskania niezależności oraz tworzenia zastępczej władzy religijno-politycznej ${ }^{18}$. Wszystko to nie pozostaje bez wpływu na kształt orędzia Biblii.

Także Nowy Testament wskazuje na konieczną inkulturację orędzia Ewangelii wpierw przez to, że Syn Boży staje się konkretnym człowiekiem. Jezus z Nazaretu co do przynależności narodowej, religijnej i kulturowej jest Żydem wychowanym i działającym przede wszystkim w Galilei ${ }^{19}$. Dzieli On z Apostołami wspólne doświadczenie narodowe, religijne i kulturowe, co sprawia, że nie ma potrzeby na tym etapie inkulturowania orędzia o królestwie Bożym. Konieczność taka pojawia się jednak w momencie przekraczania przez Ewangelię granic o charakterze religijnym i narodowym (Żydzi, Samarytanie, Grecy) oraz językowo-kulturowym (Żydzi-Hebrajczycy, Żydzi-Helleniści - greckojęzyczni mieszkańcy wschodniej części Cesarstwa Rzymskiego) ${ }^{20}$. Już porównanie „formy” oraz „tworzywa” nauczania Jezusa i Pawła ujawnia, jak bardzo kultura miejska, w której Apostoł Narodów się wychował, wpłynęła na inkulturację orędzia w czasie jego ewangelizacji ${ }^{21}$. Nie ma potrzeby dodawać, że inkulturacja była i jest podejmowana w kolejnych postępach ewangelizacyjnych Kościoła (także w Polsce ${ }^{22}$ ), natomiast trzeba podkreślić fakt, że współczesny Kościół katolicki stanowi kontynuację jedynie jednego z trzech kierunków wczesnochrześcijańskiej inkulturacji2 ${ }^{23}$.

${ }^{18}$ Por. A. FeldtKeller, Inkulturation. II. Biblisch-theologisch, [w:] Lexikon für Theologie und Kirche, dz. cyt., t. 5, s. 505-506.

${ }^{19}$ Podkreśla to bardzo mocno adhort. apost. Ecclesia in Africa, 60.

${ }^{20}$ Można także mówić o „transplantacji idei” w świat kultury grecko-rzymskiej, jak czyni to M. Skierkowski w omówieniu dzieła G. Vermesa, Jezus Żyd. Ewangelia w oczach historyka, Kraków 2003 - por. Jezus Gezy Vermesa. Prezentacja i krytyka, „Collectanea Theologica” 75 (2005) nr 2, s. 99.

${ }^{21}$ Traktuje o tym m.in. doskonała monografia: W. A. MeEks, The First Urban Christians. The Social World of the Apostle Paul, New Haven, Conn. 1983.

${ }^{22} \mathrm{Na}$ temat inkulturacji orędzia biblijnego w polskiej tradycji: T. JELONEK, Inkulturacja Biblii w Polsce, [w:] Z badań nad Biblia. Prace katedry Teologii i Informatyki Biblijnej Wydziału Teologicznego Papieskiej Akademii Teologicznej w Krakowie, t. 5, Kraków 2002, s. 27-47.

${ }^{23}$ Z Jerozolimy chrześcijaństwo rozszerza się w trzech kierunkach: (1) Zachodnia Syria (Antiochia) - Mała Azja (Efez) - Grecja (Korynt) - Rzym; (2) Wschodnia Syria - Mezopotamia - Persja - Indie; (3) Egipt - Abisynia (wyraża to tradycja o Marku w Aleksandrii). Dalsze dzieje Kościoła tak się toczą, że dzisiejsze chrześcijaństwo europejskie stanowi przedłużenie pierwszej z tych tradycji, gdy inne zostały zmarginalizowane lub przysłonięte przez chrześcijaństwo, które przyszło z Europy; por. A. FeldTKeller, Inkulturation. II. Biblischtheologisch, art. cyt., s. 505-506. 


\section{Potrzeba ekskulturacji}

Inkulturacja stanowi „proces głęboki i całościowy, który dotyczy zarówno orędzia chrześcijańskiego, jak też refleksji i konkretnej działalności Kościoła. Jest to również proces trudny, ponieważ nie może w żadnej mierze naruszyć specyfiki i integralności wiary chrześcijańskiej" (Jan Paweł II, enc. Redemptoris missio, 52). Choć to stwierdzenie encykliki wskazuje jednoznacznie na to, jak ważny i odpowiedzialny jest proces inkulturacji, to jednak nauczanie Kościoła dotyczące szczegółów jest skromne ${ }^{24}$. W przywołanej ostatnio encyklice, która winna być pod tym względem programowa, znajdziemy jedynie ,pewne wskazania”. Według więc Redemptoris missio „właściwy proces inkulturacji winien kierować się podwójną zasadą: «zgodności z Ewangelią» i «jedności Kościoła powszechnego»" (nr 54). W adhortacji apostolskiej Ecclesia in Africa do dwóch zasad: „zgodności z orędziem chrześcijańskim i komunii z Kościołem powszechnym” zostaje dołączone jedno zastrzeżenie: „W każdym przypadku należy wystrzegać się wszelkiego synkretyzmu” ( $\mathrm{nr}$ 62).

Z przeglądu określeń inkulturacji oraz jej przejawów zarówno w tekstach biblijnych, jak i w różnych przykładach inkulturowania orędzia biblijnego wynika, że nowa kultura jest oceniana co do swej zawartości w świetle głoszonego orędzia. W tym dialogu i wzajemnej wymianie z nowej kultury można przyswajać tylko te treści, które są niesprzeczne z orędziem zawartym we wcześniejszej formie inkulturacji. Takie podejście do inkulturacji przynosi pożądane ubogacenie, które podkreśla dokument Interpretacja Biblii w Kościele: „Z jednej strony bogactwa zawarte w różnych kulturach pozwalają Słowu Bożemu wydawać nowe owoce, a z drugiej strony światło Słowa Bożego pozwala dokonywać wyboru w tym, co wnoszą kultury, aby odrzucić elementy szkodliwe i sprzyjać rozwojowi elementów wartościowych" (tł. D. Piekarz) ${ }^{25}$.

Gwałtowne przemiany cywilizacyjne ujawniają potrzebę inkulturacji, która okazuje się konieczna już nie tylko w krajach misyjnych, ale także społeczeństwach tradycyjnie chrześcijańskich. Nie można bowiem głosić orędzia chrześcijańskiego w formie, która byłaby niezrozumiała lub poważnie utrudniała przyjęcie depozytu wiary. Z tym wiąże się problem rozgraniczenia tego, co istotne w orędziu, oraz tego, co stanowi tylko

${ }^{24}$ Proces inkulturacji oraz związany z nim proces aktualizacji przybliża opracowanie: S. HaręzGa, Droga stowa Bożego od jego zrozumienia do inkulturacji, [w:] Biblia w Kościele, Kraków 1998, s. 27-43.

${ }^{25}$ Interpretacja Biblii w Kościele, IV. B, [cyt. za:] Z badań nad Biblia, t. 2, dz. cyt., s. 179. Pomijamy zagadnienie fałszywej inkulturacji, która może przybierać dwie formy: powierzchowną tylko ,adaptację” orędzia ewangelicznego lub synkretystyczne zmieszanie treści, w tym i takich, które $\mathrm{z}$ autentycznym orędziem są nie do pogodzenia. 
jego kulturową formę. Właśnie próba sprecyzowania tego, co istotne i niezmienne w orędziu, zanim będzie ono inkulturowane, to ekskulturacja, która jest przedmiotem tego artykułu. Tego typu refleksja wymaga zastosowania odpowiednich narzędzi wobec orędzia, które zawsze jest historycznie zakorzenione i kulturowo uwarunkowane.

Co najmniej dwoje polskich naukowców używa terminu „ekskulturacja”. Pierwszym jest Anna Wierzbicka ${ }^{26}$, językoznawca, drugim ks. Arkadiusz Baron, patrolog, tłumacz i badacz rozwoju doktryny chrześcijańskiej. A. Wierzbicka proponuje, by dla „wykorzenienia” ze starej kultury (ekskulturacja) wyrazić dostępne nam w brzmieniu Ewangelii orędzie w tzw. pojęciach prostych i elementarnych ${ }^{27}$. Jako przykład niech posłuży logion „miłujcie waszych nieprzyjaciół”, którego eksplikacja według tej autorki brzmi: ,jeśli ktoś chce robić tobie złe rzeczy, będzie dobrze, jeżeli ty nie będziesz chciał robić złych rzeczy temu komuś z tego powodu, będzie dobrze, jeżeli będziesz chciał robić dobre rzeczy dla tego kogoś"28.

A. Baron wskazuje na doświadczenie historyczne Kościoła wyrażone szczególnie w tekście biblijnym jako na wzór dla koniecznej także dzisiaj ekskulturacji. W swojej monografii pisze on: „dysponujemy przykładami objawionej ekskulturacji Ewangelii z judaizmu, które znajdujemy w decyzjach tak zwanych Synodów Apostolskich, w Dziejach Apostolskich oraz w listach Nowego Testamentu. Ich lektura poświadcza, że nie była ona łatwa ani oczywista, ani nie przebiegała bezkonfliktowo"29. A. Baron przybliża okoliczności tego decydującego dla rozwoju Kościoła procesu, pisząc: „misjonarze pierwszych wieków głoszący Ewangelie w basenie Morza Śródziemnego podejmowali nie tylko problemy pojęciowe, ale przyszło się im mierzyć z wyzwaniami ekskulturacji chrześcijaństwa z judaizmu oraz jego inkulturacji w świat helleńsko-rzymski. Wiązało się to z przejściem z jednej cywilizacji do innej, z jednego światopoglądu do innego, z jednego sposobu myślenia do innego. Ponadto trzeba było określić to, co z judaizmu obowiązuje w chrześcijaństwie, a co nie, jak również to, co ze świata pogańskiego należy rugować, a czego nie. Proces ten dotyczył nie tylko światopoglądu, ale także przepisów prawa i moralności”30.

${ }^{26}$ Por. A. WierzBicka, Co mówi Jezus? Objaśnianie przypowieści ewangelicznych w stowach prostych $i$ uniwersalnych, przeł. I. Duraj-Nowosielska, Warszawa 2002, s. 26.

${ }^{27}$ Omówienie tych pojęć w: A. WierzBicka, Co mówi Jezus?..., dz. cyt., s. 16-17.

${ }^{28}$ Tamże, s. 18.

${ }^{29}$ A. BARon, Neoplatońska idea Boga a ewangelizacja. Analiza anonimowego komentarza do „Parmenidesa” Platona na tle myśli plotyńsko-porfiriańskiej, Kraków 2005, s. 8 (Myśl Teologiczna, 50).

${ }^{30}$ A. BARON, Neoplatońska idea Boga a ewangelizacja..., dz. cyt., s. 8. 
Ocena obu przedstawionych propozycji ekskulturacji wymaga jednak osobnego i bardziej obszernego opracowania, w niniejszym bowiem szło jedynie o zasygnalizowanie potrzeby takiego procesu.

Kraków

KS. ROMAN PINDEL

Summary

The need of acculturation in the process of inculturation

The article intends to convince that acculturation should be distinguished in the process of inculturation. First, the author defines the term "inculturation", according to the teaching of the Church. Next, he gives some biblical examples of inculturation. It has been stressed that the process of inculturation must be bidirectional (incorporating the Gospel into the culture and adopting these cultural elements which are not in contradiction with the Gospel).

Both the Bible and the Church indicate that a properly conducted process of inculturation is the condition which must be met for the target culture to accept the Gospel. In the last paragraph, the author singles out the conditions to be met by inculturation. Another process, namely acculturation which aims at depriving the Gospel of its cultural conditions, needs to be added to the list. Two writers have noticed the need of doing so: Anna Wierzbicka, the linguist, and Fr. Arkadiusz Baron, the patrologist (transl. by Zygmunt Kostka). 